\title{
Performance assessment of an Indalma hydro-turbine
}

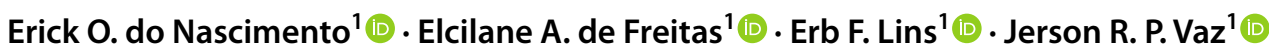

Received: 4 July 2020 / Accepted: 26 November 2020 / Published online: 5 December 2020

(c) Springer Nature Switzerland AG 2020

\begin{abstract}
Hydro-turbines for small heads have recently attained considerable attention as they show the possibility of achieving a good power performance. In Brazil, electricity is highly dependent on the hydroelectric generation due to high water availability and low long-term cost. For generation at smaller scales, conventional turbines such as Kaplan, Pelton and Francis generally do not present satisfactory efficiency and they typically have a high installation cost. In this way, there are some alternatives for small hydropower plants; one of them is the Indalma turbine, which was invented and built in the eastern Amazon region. The differential of this turbine is the shape of the blades and the shape of the spiral casing, having its efficiency experimentally verified by the National Reference Center in Small Hydroelectric Plants (CERPCH/ UNIFEI-MG-Brazil). Since the design of this turbine was performed almost empirically, there is a need for an in-depth study of the pressure and velocity fields, as well as other phenomena that commonly occur in hydraulic turbines. Thus, this work presents a performance assessment of an Indalma pico-turbine through computational fluid dynamics, using a Reynolds-averaged Navier-Stokes formulation. As a result, the Indalma turbine has a good performance among conventional turbines at the nominal operating point. The highest turbine efficiency of $80.8 \%$ is found at a flow rate of $0.012 \mathrm{~m}^{3} / \mathrm{s}$ and a rotational speed of $1460 \mathrm{rpm}$. Additionally, the results yield good agreement with experimental and theoretical data available in the literature, demonstrating that Indalma turbine is a good alternative for small hydropower plants.
\end{abstract}

Keywords Indalma turbine $\cdot$ Hydrodynamic analysis $\cdot$ Computational fluid dynamics

\section{Introduction}

Electricity generation in Brazil is highly dependent on hydroelectric power. This is due to the high availability of this energy source, enabling the implementation of low cost projects, such as generating plants that have considerable lower cost installed capacity when compared to other sources [1].

Due to the high energy demand and great diversity of environments in Brazil, these plants have a great role to ensure constant energy supply, in safely way and low environmental impact. For those reasons, generating plants should have different characteristics to meet the needs of each project in order to have the best efficiency in the use of hydraulic resources [2]. Hydraulic energy may be harnessed through different types of turbines which are chosen depending on the characteristics of the local hydraulic potential, such as head and flow rate. Among the conventional turbines, Pelton operates in plants that usually have large head and low flow rate. Its impeller consists of rods connected to shells. Also, a distributor is formed by water jet nozzles that impact the shell blades, tangentially to the impeller. Kaplan turbines are axial flow turbines, in which it is usually built based on the propeller turbine. This turbine operates most efficiently in locations with net head of up to $80 \mathrm{~m}$ [3]. Francis turbines operate efficiently over a wide range of head, from 45 to $700 \mathrm{~m}$, at flow rates from 10 to $700 \mathrm{~m}^{3} / \mathrm{s}$ [3]. Hence, Francis turbines are the most versatile and widely used in generating hydroelectric plants.

Erick O. do Nascimento, oliveira94n@gmail.com | ${ }^{1}$ Graduate Program in Mechanical Engineering, Institute of Technology, Federal University of Pará, R. Augusto Correa, No 1, Guamá, Belém, PA, Brazil. 
In addition to these turbines, there are unconventional ones. Usually applied in remote or isolated regions, having extremely low costs or even because the conventional turbines presented before can not efficiently use the water resources of small net heads or flow rates. In these types of application, dams are not commonly used, minimizing even more costs and environmental impact [4].

One such unconventional turbine is the Indalma turbine, which can be classified from the flow behavior as centripetal-axial. It is a turbine developed empirically and produced in the Amazon region in a rustic way, but it has been satisfactorily served several micro-hydroelectric plants in the eastern part of the Amazon.

This turbine has a triangular-shaped spiral case that conducts fluid to the rotor. The rotor blades have constant section, and they are arranged in the radial direction. The blades are curved longitudinally to the axis, so the flow becomes almost axial [5].

The first Indalma turbine system installed in the Amazon had a generating capacity of $5 \mathrm{kVA}$. Following the success of this facility, the turbine was spread throughout western of the state of Pará, Brazil. In 2010, 44 picocentrals and 18 micro-hydropower (MHP) were installed to meet local demand. Table 1 shows the main projects using Indalma turbines, their respective power, number of families served and the size of the transmission lines [6].

Since the design of this turbine was performed almost empirically [7, 8], there is a need for an in-depth experimental and numerical studies, including phenomena such as vibration, cavitation, recirculation and hydrodynamic loading to increase efficiency in power generation and system life [9]. Only a few works are available in the literature describing Indalma turbine [10, 11]. Those works do not develop any detailed studies on the flow behavior through the turbine's system, including evolute and runner. For example, an assessment of three diffusers was made in [12], in order to experimentally evaluate turbine efficiency improvements. But, this study did not investigate the hydrodynamic behavior of the turbine. Only the work of [13] shows a very interesting study on Indalma turbine, in which a simplified experimental and numerical investigations are done. This demonstrates the importance

Table 1 Main projects using Indalma turbines [6]

\begin{tabular}{lllll}
\hline & Name of MHP & Power (kVA) & $\begin{array}{l}\text { Number of } \\
\text { families }\end{array}$ & Network $(\mathrm{km})$ \\
\hline 1 & Creporizão & 240 & 420 & - \\
2 & Sombras Santa & 160 & 380 & 48 \\
3 & São Jorge & 160 & 180 & - \\
4 & Corta Corda & 150 & 180 & 37 \\
5 & Piranha & 150 & 350 & 61 \\
\hline
\end{tabular}

of more studies on Indalma turbine as an alternative for energy generation using small net heads.

Generally, the study of flow in hydraulic turbines is performed using reduced models. Due to the high cost of experimental tests, computational fluid dynamics (CFD) is an alternative for turbomachinery analysis [14], as it allows to evaluate the flow behavior in the turbine for several operating conditions. CFD analysis is attractive mainly due to the level of information obtained from the flow, as well as the modeling of complex geometries, including flows with high rotations.

In the present work, the hydrodynamic study of an Indalma pico-turbine using CFD was done in order to evaluate its operation at low head. In this regard, pressure and velocity fields acting on the Indalma turbine components were obtained and described. The visualization of these fields is important due to the fact that vortices creates low pressure regions, and the phenomenon of cavitation may occur. Efficiency and power curves were obtained for net heads of $4,5.5$, and $7 \mathrm{~m}$ to evaluate the performance of the turbine at low head. As a result, the turbine has a good performance among conventional ones at the nominal operating point. The highest turbine efficiency of $80.8 \%$ is found at a flow rate of $0.012 \mathrm{~m}^{3} / \mathrm{s}$ and a rotational speed of $1460 \mathrm{rpm}$. Additionally, the results yield good agreement with experimental and theoretical data available in the literature, demonstrating that Indalma turbine is a good alternative for small hydropower plants.

\section{Indalma turbine}

The Indalma turbine is a mixed reaction hydraulic machine of an unconventional type, mostly based on the Francis turbine. This turbine was invented, patented and developed being manufactured by Indalma company, located in the city of Santarém, in the state of Pará, in order to meet the needs of small hydroelectric power plants in the Amazon region [8]. This machine is manufactured with flow inlet and outlet diameters ranging from 0.1016 to $0.635 \mathrm{~m}$, depending on where it is used [10]. In Fig. 1, it is shown a typical installation of this turbine.

The Indalma turbine has its configuration shown in Fig. $1 \mathrm{~b}$, d, being composed of a triangular spiral case, a manual valve controller, rotor, draft tube. There is not, like in the Francis turbine, a distributor or a sophisticated flow control mechanism. Because of its simple and robust construction, compared to conventional turbines, its price is lower than other equivalent machines. According to [10], the Indalma turbine is able to work safely in the working conditions of the Amazon region and presents satisfactory results, considering the available head and flow in the region. 

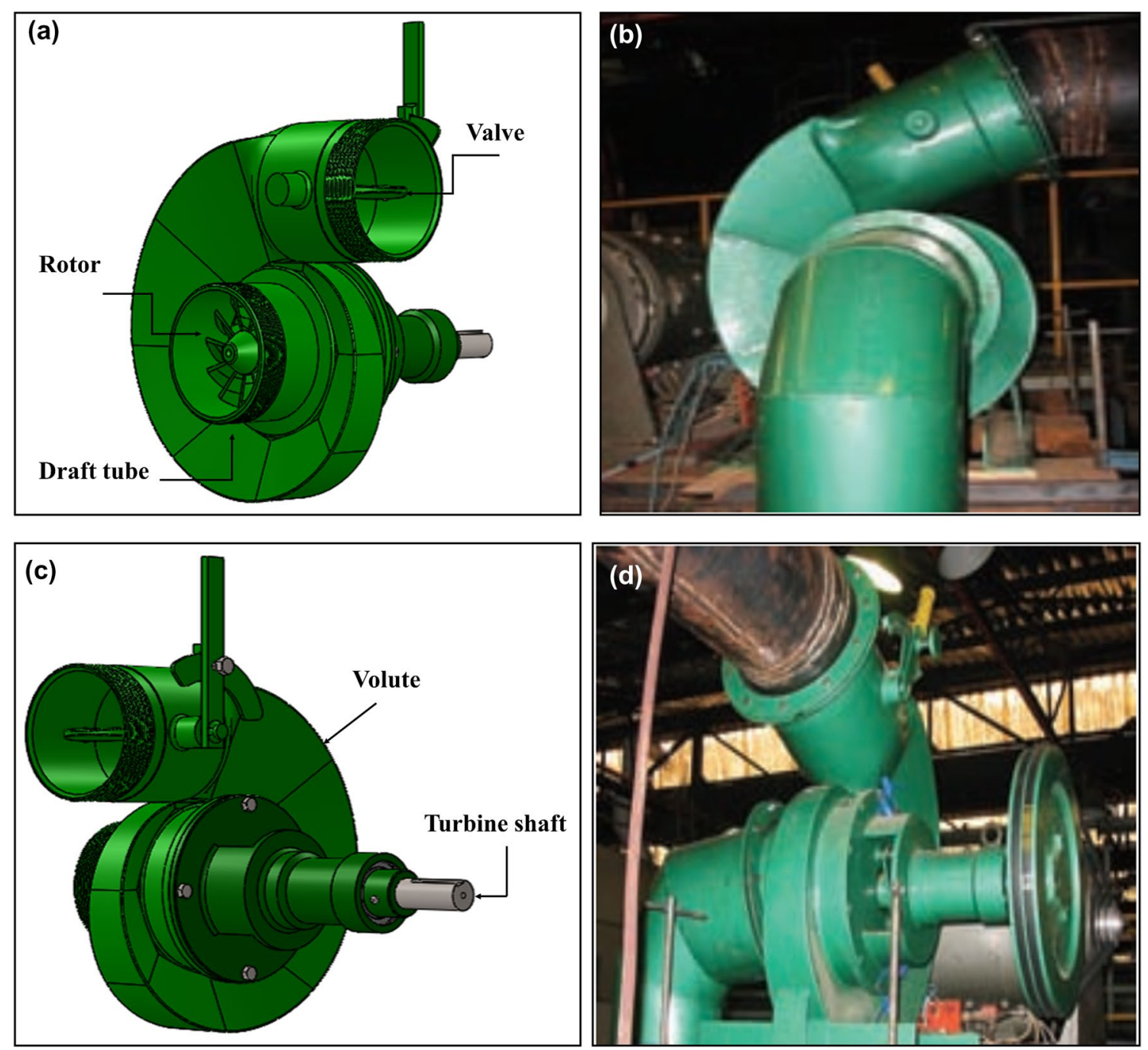

Fig. 1 a Turbine flow outlet side. b Turbine shaft side [11]
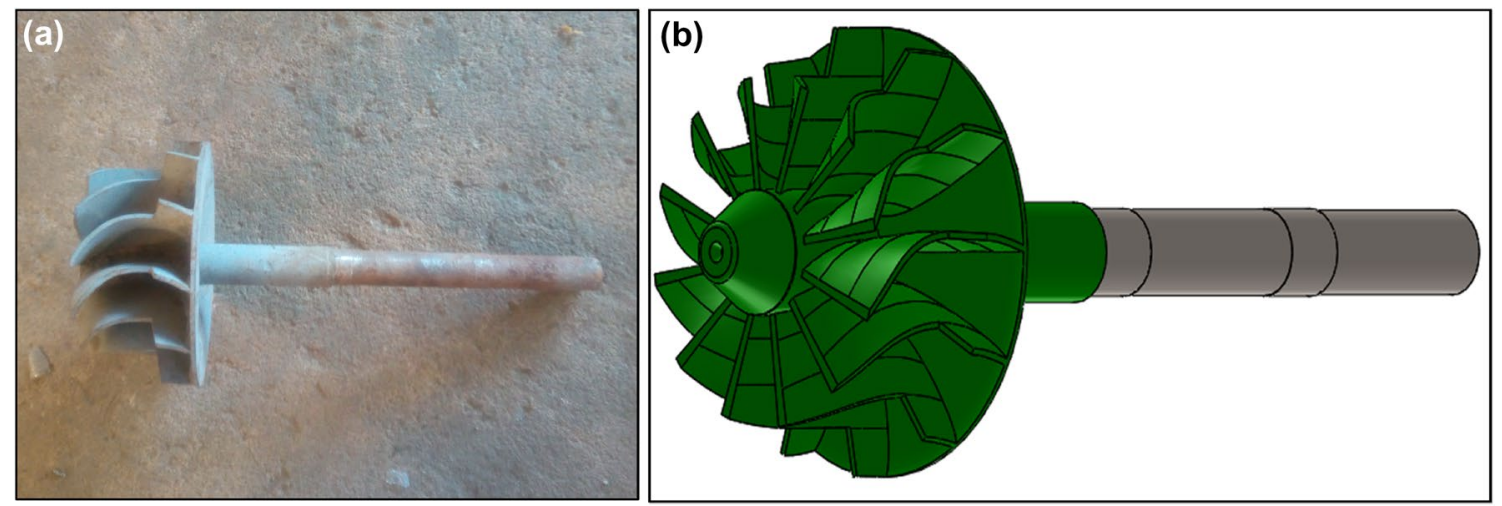

Fig. 2 a Arrangement of blades on hub. b Rotor computational model 
The turbine rotor is shown in Fig. 2, which can be analyzed into two parts, the first section of the blades being arranged in the radial direction and in the center of the rotor a sudden change occurs, forcing the flow to have an axial behavior.

Due to the absence of a distributor or a sophisticated flow controller, it facilitates the deployment of this turbine in small hydraulic uses [8]. Thus, these turbines are employed in small dams with a minimum head of $4 \mathrm{~m}$, for a flow rate of $0.35 \mathrm{~m}^{3} / \mathrm{s}$ on each turbine. Its efficiency was tested by the National Reference Center for Small Hydroelectric Plants of the Federal University of Itajubá (CERPCH/ UNIFEI-MG) [7].

The results found by [10] showed that the two turbines, connected to the same generator, have hydraulic efficiency about $70 \%$ at the ideal operating condition, for a flow rate of $1 \mathrm{~m}^{3} / \mathrm{s}$, with rotation of $534 \mathrm{rpm}$. In this case, the turbine was able to produce about $56 \mathrm{~kW}$. In 2014, modifications were made to the turbine to improve its performance experimentally. [8] showed that these modifications increased turbine performance to $79 \% \pm 4.5 \%$ at the best condition. In the work of [12], it has been shown that in an Indalma pico-turbine, the presence of a diffuser would increase its hydraulic efficiency by up to $82.22 \% \pm 4.93 \%$.

Several tests were performed on a $0.1524 \mathrm{~m}$ Indalma turbine, through which the speed of the no-load turbine was about $1300 \mathrm{rpm}$ with a flow rate of $0.01 \mathrm{~m}^{3} / \mathrm{s}$. This turbine generated a maximum power of $3.367 \mathrm{~kW}$ at 696 rpm and flow rate of $0.04 \mathrm{~m}^{3} / \mathrm{s}[4,13]$.

\section{Numerical approach}

\subsection{Computational modeling}

The three-dimensional geometry of the Indalma turbine used in this study was based on the work of [5]. The geometry can be separated into five parts: volute, valve, rotor, draft tube and turbine shaft, as shown in Fig. 1.

The turbine flow modeling was performed using CFD through the finite volume method. The velocity and pressure fields were determined for an incompressible and turbulent flow considering steady-state regime. The effect of turbulence is calculated by Reynolds-averaged Navier-Stokes (RANS) equations [36]. In this method, the decomposition is performed through Eqs. (1) and (2):

$\mathbf{u}=\overline{\mathbf{u}}+\mathbf{u}^{\prime}$

$p=\bar{p}+p^{\prime}$ where $\overline{\mathbf{u}}$ and $\bar{p}$ are the mean component of velocity vector $\mathbf{u}$ and pressure $p$, respectively, and $\mathbf{u}^{\prime}$ and $p^{\prime}$ are the fluctuation components of these variables. The conservation equations of mass and momentum in the form of averages are rewritten, according to Eqs. (3) and (4) [15]:

$\nabla \cdot \overline{\mathbf{u}}=0$,

$\rho \frac{\partial \overline{\mathbf{u}}}{\partial t}+\rho \overline{\mathbf{u}} \cdot \nabla \overline{\mathbf{u}}=-\nabla \bar{p}+\nabla \cdot(2 \mu \mathbf{S}-\mathbf{R})+\rho \mathbf{f}$

where $\rho$ is the density, $\mu$ is the dynamic viscosity and $\mathbf{f}$ represents a body force per unit volume, such as Coriolis and centrifugal contributions. $\mathbf{S}=\frac{1}{2}\left(\nabla \overline{\mathbf{u}}+\nabla^{T} \overline{\mathbf{u}}\right)$. The terms present in Eqs. (3) and (4) are written as a function of the velocity vectors $\overline{\mathbf{u}}$ and the pressure $\bar{p}$. The Reynolds stress tensor $\mathbf{R}=\rho \overline{\mathbf{u}^{\prime} \times \overline{\mathbf{u}}^{\prime}}$ is the only term that is influenced by velocity fluctuations [16]. This term is modeled using the mean flow variables, rather than an explicit equation [17], using the shear-stress transport $\kappa-\omega$ (SST $\kappa-\omega)$. This was chose in this work since this model provides satisfactory results for this type of problem, as shown in $[14,18-20]$.

The SST $\kappa-\omega$ is a combination of the standard $\kappa-\omega$ and $\kappa-\varepsilon$, as further described by [21]. This approach addresses the advantages of both previous models in different flow regions by activating the default $\kappa-\omega$ model for near-wall region and the standard $\kappa-\varepsilon$ model far from the surface. For this reason, the SST model proved to be more accurate than other models [22]. The SST $\kappa-\omega$ is similar to the standard $\kappa-\omega$, where the turbulence kinetic energy $(\kappa)$ and the specific dissipation rate $(\omega)$ are obtained from equations (5) and (6):

$\frac{\partial}{\partial t}(\rho \kappa)+\nabla(\rho \kappa \mathbf{u})=\nabla \cdot\left(\Gamma_{\kappa} \nabla \kappa\right)+G_{\kappa}-Y_{\kappa}+S_{\kappa}$

$\frac{\partial}{\partial t}(\rho \omega)+\nabla(\rho \omega \mathbf{u})=\nabla \cdot\left(\Gamma_{\omega} \nabla \omega\right)+G_{\omega}-Y_{\omega}+D_{\omega}+S_{\omega}$

where $G_{\kappa}$ is the turbulent kinetic energy source term, $G_{\omega}$ is the dissipation equation source term. $\Gamma_{\kappa}$ and $\Gamma_{\omega}$ are the effective diffusion coefficients for $\kappa$ and $\omega$, respectively. $Y_{\kappa}$ and $Y_{\omega}$ are the divergence terms for $\kappa$ and $\omega . D_{\omega}$ is the orthogonal divergence term. $S_{K}$ and $S_{\omega}$ are source terms [23].

The discretization of the domain used in the numerical simulation is one of the most important parameters, as it directly influences the solution found for the velocity and pressure fields. In the present work, the numerical mesh is parameterized using the dimensionless distance of wall $y^{+}$as

$y^{+}=\frac{\rho y u^{+}}{\mu}$ 
where $u^{+}$is the wall shear velocity and $y$ is the dimensional distance to wall. The near-wall region can be subdivided into three zones. The first of these sub-layers is laminar (viscous), which is characterized by local low Reynolds, so viscosity is predominant in the transfer of momentum. Subsequently, one region which the turbulence intensifies forming a transition region between laminar and turbulent sub-layers. In the last sub-layer there is a local high Reynolds flow, where turbulence is predominant. The SST $\kappa-\omega$ model defines the approach that will be applied for the $y^{+}$parameter calculation. In order to obtain a satisfactory solution of the boundary layer, it is necessary to refine the computational mesh to ensure the value of $y^{+}$less than or equal to 1 [36]. Hence, the mesh will be solved including the viscous sub-layer region. Therefore, in order to meet this criterion, near the surface a prismatic layer was generated to adjust this parameter.

To perform the simulation, the valve was considered fully opened and a single domain was created to encompass the rotor and the draft tube to simplify the problem. From these considerations, the computational domains were generated corresponding to the volume from the volute (stationary element), as shown in Fig. 3a, and another for the rotor (rotating element), as illustrated in Fig. 3b.

The boundary conditions are applied to the computational domain through CFX solver. In Fig. 3a, the computational domain of the volute and its boundary conditions are shown, wherein the blue colored region corresponds to the solid casing surface (WV) with a non-slip configuration, so the relative velocity of the fluid particle in the wall is zero. In the INLET, a Dirichlet boundary condition was set, in which the input velocity results in a constant normal mass flow is performed. The turbulence in the inlet flow has $5 \%$ of intensity, while the turbulent viscosity ratio is considered equal to 10 .

It was necessary to create an interface between the stationary mesh (green colored region in Fig. 3a), and the rotating mesh (green colored region in Fig. 3b) to define a Frozen connection Rotor, where the components of the volute domain are transformed into a movable reference system by entering the centrifugal and Coriolis accelerations, allowing the local characteristics of the flow to be translated through this interface.

Figure $3 \mathrm{~b}$ shows the rotating domain of the mesh, where the blue region represents the rotor (blades and hub) and the suction tube wall (ROTOR and WR, respectively), in which the boundary condition was set as a nonslip condition. In the OUTLET region, the boundary condition was set as outlet pressure.

\section{Experimental data}

A schematic drawing of the experimental test configuration is illustrated in Fig. 4. The test was designed and built at the Faculty of Gama of the University of Brasilia, with the purpose of performing tests on pico- and micro-turbines in different operating configurations, varying head, flow rate, inlet and outlet pressures [5].

To carry out the simulations, manipulations and experimental measurements, the following equipments were installed: a pump to generate the necessary flow with the aid of an inverter, which can vary this parameter more easily; distribution valves to allow variation in the drop height; a Prony brake to measure the power on the shaft using a rotation sensor and strain gauges; a V-notch reservoir to measure flow and pressure gauge
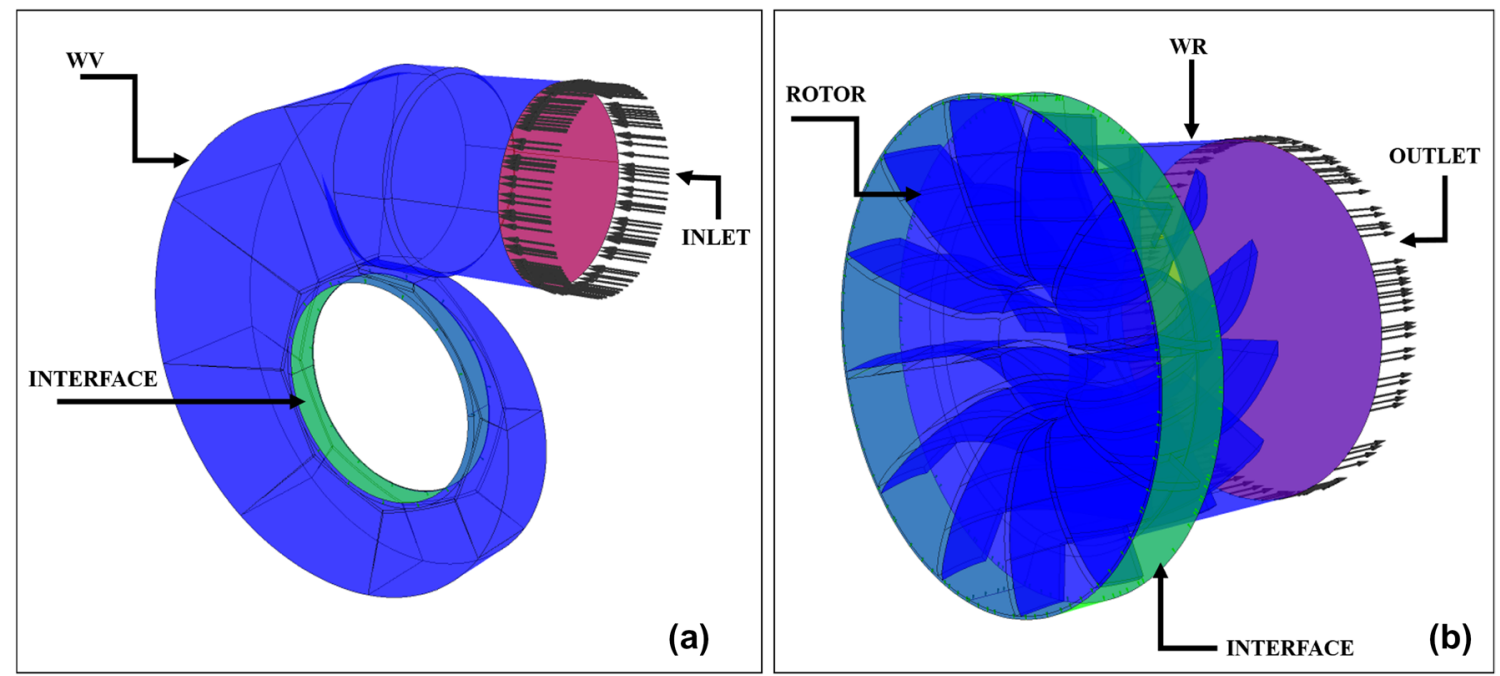

Fig. 3 a Stationary domain. b Rotating domain 
Fig. 4 Schematic overview of the experimental test setup [5]

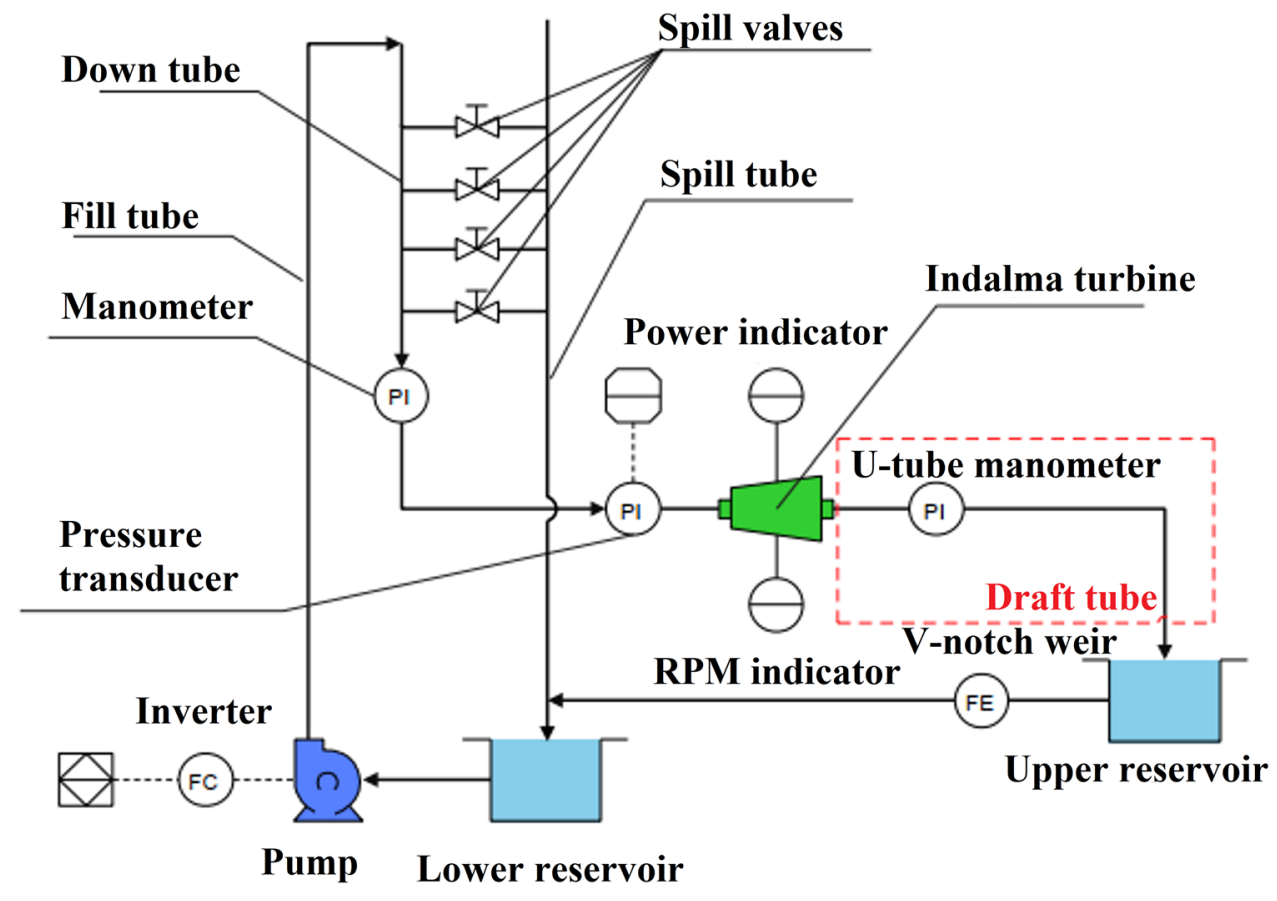

The system operation can be described as follows. Primarily, it consist of pumping water from the lower reservoir to the fill tube. If necessary some of the water is diverted through spill valves into the spill tube which will return to the lower reservoir. The remaining water goes through the lower tube until it reaches the turbine which is subsequently discharged into the spillway (upper reservoir). Subsequently, by gravity the water flows to the lower reservoir ending the cycle.

Table 2 shows some parameters and data obtained from the test bench for a head of 4, 5.5 and $7 \mathrm{~m}$ with submerged draft tube, where the pump is controlled by an inverter to ensure the flow required to pass through the turbine. Spill valves in combination with the inverter perform the function of controlling the head at the inlet turbine. The uncertainties of the experimental measurements for rotation, flow rate and pressure are $0.53 \%$, $1.69 \%$ and $0.48 \%$, respectively.

A brake is used to measure shaft power through strain gauges, as well as a rotational sensor to measure the turbine rotational speed $(N)$. The upper reservoir has a $V$-notch spillway to measure water flow. Pressure gauges at the turbine inlet $\left(P_{\text {in }}\right)$ and outlet $\left(P_{\text {out }}\right)$ were used to measure the pressure in these regions, in addition to the net head and turbine efficiency $(\eta)$.

Table 2 Measurements at 4, 5.5 and $7 \mathrm{~m}$ head with submerged draft tube

\begin{tabular}{|c|c|c|c|c|c|c|c|c|}
\hline \multicolumn{3}{|l|}{$4 \mathrm{~m}$} & \multicolumn{3}{|l|}{$5.5 \mathrm{~m}$} & \multicolumn{3}{|l|}{$7 \mathrm{~m}$} \\
\hline Flow rate $(\mathrm{kg} / \mathrm{s})$ & Rotation (rpm) & $\begin{array}{l}\text { Outlet } \\
\text { pressure } \\
(\mathrm{MPa})\end{array}$ & Flow rate $(\mathrm{kg} / \mathrm{s})$ & Rotation (rpm) & $\begin{array}{l}\text { Outlet } \\
\text { pressure } \\
(\mathrm{MPa})\end{array}$ & Flow rate $(\mathrm{kg} / \mathrm{s})$ & Rotation (rpm) & $\begin{array}{l}\text { Outlet } \\
\text { pressure } \\
(\mathrm{MPa})\end{array}$ \\
\hline 10.57 & 1160 & 1.02 & 11.57 & 1460 & 1.04 & 13.16 & 1600 & 1.04 \\
\hline 12.56 & 900 & 1.00 & 13.16 & 1270 & 1.02 & 15.45 & 1300 & 1.02 \\
\hline 13.46 & 790 & 9.94 & 14.56 & 1070 & 1.00 & 16.35 & 1150 & 1.00 \\
\hline 13.66 & 590 & 9.93 & 15.15 & 930 & 9.97 & 17.35 & 1050 & 9.96 \\
\hline 14.06 & 400 & 9.94 & 15.95 & 830 & 9.94 & 17.85 & 830 & 9.97 \\
\hline 14.26 & 210 & 9.95 & 16.15 & 670 & 9.93 & 18.15 & 580 & 9.98 \\
\hline 14.56 & 110 & 9.98 & 16.35 & 500 & 9.95 & 18.44 & 320 & 9.98 \\
\hline - & - & - & 16.65 & 170 & 9.97 & 18.44 & 160 & 1.00 \\
\hline
\end{tabular}


Table 3 Measurements at $5.5 \mathrm{~m}$ head with submerged draft tube

\begin{tabular}{ll}
\hline Parameter & Value \\
\hline Number of blades & 12 \\
Power & $379.00 \mathrm{~W}$ \\
Head & $5.50 \mathrm{~m}$ \\
Inlet mass flow & $15.15 \mathrm{~kg} / \mathrm{s}$ \\
Rotation & $930 \mathrm{rpm}$ \\
Outlet pressure & $99657.87 \mathrm{~Pa}$ \\
Efficiency & $46.10 \%$ \\
\hline
\end{tabular}

\section{Results and discussion}

In this section, results and discussion on the turbine performance analysis are presented. Comparisons with experimental data obtained by [5] are also carried out. Hydrodynamic characteristics of the turbine are described through the streamlines, contours of pressure and velocity field.

\subsection{Numerical validation}

A study of the configuration and convergence of the mesh was employed to assure reliable and accurate results. The configuration adopted for the Indalma pico-turbine to perform this procedure is described in Table 3.
The parameters employed in this simulation are the values obtained for the best pico-turbine operating condition found in the experimental data of [5]. To assess the convergence of the solution, it was configured as a stopping criterion that the maximum root mean square (RMS) of the momentum and mass conservation equations should not exceed $10^{-4}$ or 600 iterations. [24-26].

This comparison is important to assure the mesh independence of the generated model. For this analysis, beside the residue evaluation, the power generated by the turbine rotor was taken as the solution convergence parameter. The computational model has been discretized into four different configurations, varying the size of the element in the near-wall region and in the regions away from the solid surface, as shown in Table 4. It will be described throughout this section.

In Table 4, the number of elements used in each mesh is in ascending order. The values of maximum $y^{+}$of every computational domain, the power calculated, and the difference between the values obtained in this work with the experimental one are also given.

The first mesh has $0.22 \times 10^{6}$ elements without treatment near the wall. For the second mesh, again no treatment was performed near the wall, but with $5.28 \times 10^{6}$ elements, as can be observed in Table 4. As shown in Fig. 5, the lack of refinement near the solid surface of these two
Table 4 Mesh refinement study

Fig. 5 Mesh refinement study

\begin{tabular}{|c|c|c|c|c|c|c|}
\hline \multirow[t]{2}{*}{ Mesh } & \multirow{2}{*}{$\begin{array}{l}\text { Number of } \\
\text { nodes }\left[10^{6}\right]\end{array}$} & \multirow{2}{*}{$\begin{array}{l}\text { Prismatic } \\
\text { layers }\end{array}$} & \multicolumn{2}{|l|}{$y^{+}$} & \multirow[t]{2}{*}{ Power (W) } & \multirow[t]{2}{*}{ Difference $(\%)$} \\
\hline & & & $y_{\max }^{+}$ & $y_{\mathrm{avg}}^{+}$ & & \\
\hline 1 & 0.22 & 0 & 1138.76 & 284.50 & 395.05 & 4.23 \\
\hline 2 & 5.28 & 0 & 421.56 & 56.89 & 405.14 & 6.90 \\
\hline 3 & 11.26 & 15 & 0.35 & 0.07 & 364.33 & 3.87 \\
\hline 4 & 14.15 & 15 & 0.35 & 0.06 & 366.50 & 3.30 \\
\hline
\end{tabular}

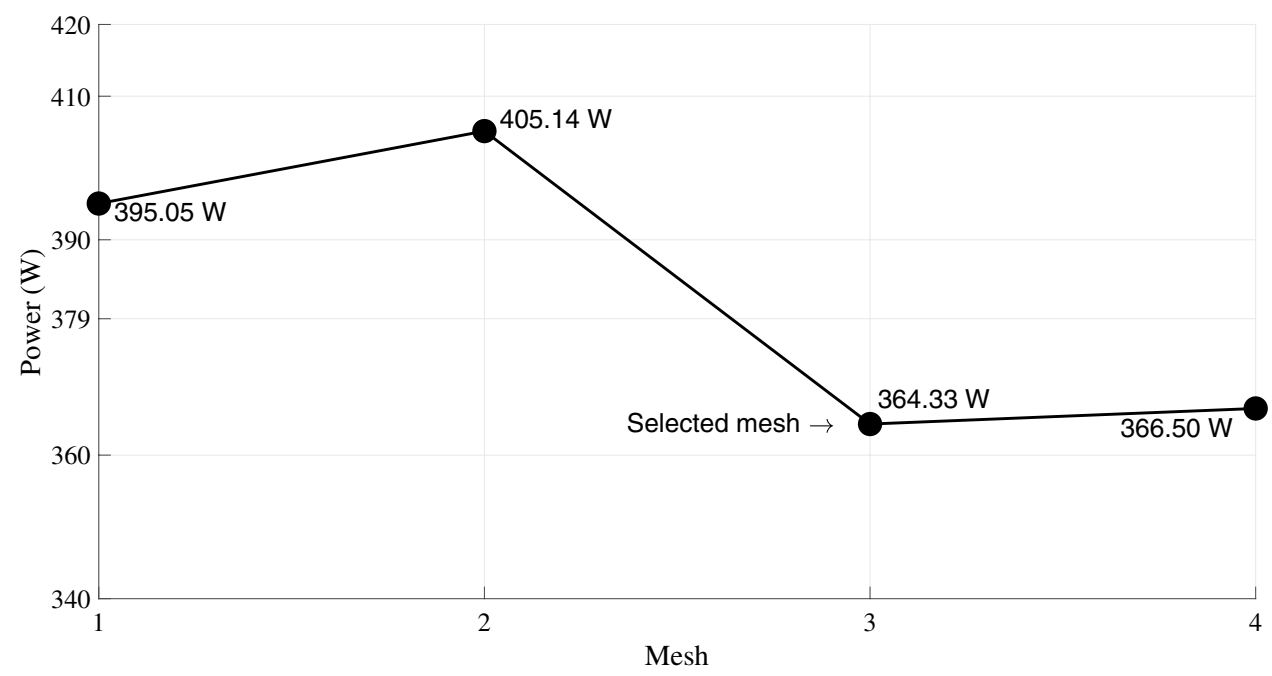


meshes affects the value found for the generated power up to $7 \%$ difference with the experimental result.

As stated before, a prismatic layer was applied to the regions near the wall to meet the required $y^{+}$value of the turbulence model employed. The mesh 3 , has $11.26 \times 10^{6}$ elements, where in the region near the wall, a prismatic layer with 15 elements was configured to capture the entire boundary layer in both domains.

After convergence the power parameter had a variation of less than $5 \%$ over the iterations. Thus, the simulations were stopped after 600 iterations where the residual values of the momentum in the directions, $x, y, z$ and mass equations were $3.42 \times 10^{-4} ; 3.53 \times 10^{-4} ; 5.59 \times 10^{-4}$ and $2.2 \times 10^{-4}$, respectively. According to [23], from $5 \times 10^{-4}$, the solution has reasonable convergence, so the residuals obtained are less than this value or close to what is required.

It can be seen in Fig. 6 the value of the power generated over iterations. Over the 300th iteration, the solution has slight variation from the value previously found. Thus, for mesh 3 , the generated power is $364.33 \mathrm{~W}$, so a difference is less than $4 \%$ from the experimental value, as shown in Table 4 and Fig. 5 . It can be verified that the computational model returns satisfactory results for the hydrodynamic behavior of the Indalma pico-turbine.

Despite the satisfactory results found, a fourth mesh with $14.15 \times 10^{6}$ elements was set using a treatment close to the wall equal to mesh 3 . As shown in Table 4, with mesh 4 , the difference between the result obtained ( $366.50 \mathrm{~W}$ ) and the experimental one was reduced. But, such a difference is subtle when compared to the value found with mesh 3, despite the considerable increase in the number of elements. Therefore, mesh 3 is adopted here because it achieved an acceptable result when compared to the experimental, even though mesh 4 obtained a closer value. The additional refinement significantly increases the computational cost and has a smaller difference, about $0.59 \%$ over the previous mesh. Hence, all analyses are performed using mesh 3.

In the rotational region, $y^{+}$does not exceed the value of 0.35 and in this domain the average $y^{+}$is 0.16 . In the stationary mesh, the maximum $y^{+}$is 0.30 , while the average $y^{+}$is 0.03 . Therefore, regions close to the wall meet the requirement for SST $\kappa-\omega$ model for a satisfactory boundary layer solution.

\subsection{Performance of the Indalma hydro-turbine}

In this subsection, the hydrodynamic characteristics of the turbine are described using the streamlines, contours of pressure and the velocity vector field. In Fig. $7 a$, the volute region has not shown significant flow recirculation, having a symmetrical flow with gradual velocity increase as the flow approaches the rotor. This is expected due to the reduction of the area through which the flow passes. Also, such a reduction increases the kinetic energy of the fluid, consequently increasing the turbine rotation, allowing more energy generation.

Figure $7 \mathrm{~b}$ shows the pressure distribution on a plane crossing the center of the volute. From this contour, it has been observed that the pressure is quite uniform along the cross-sectional plane, even with the reduction of the section. This behavior is important to provide a flow with the same characteristics approaching the rotor. This finding is also supported by the results of [24] and [27] for a Francis turbine.

The behavior of the fluid is verified through the velocity vector field. For this, a plane was made near the tip of the blade, depicting the vortex formation between the blades, resulting from the rotating action of the rotor in the fluid, as shown in Fig. 8. Note that the velocity in the recirculation region between blades may achieve
Fig. 6 Numerical stabilization of the turbine power during the simulation

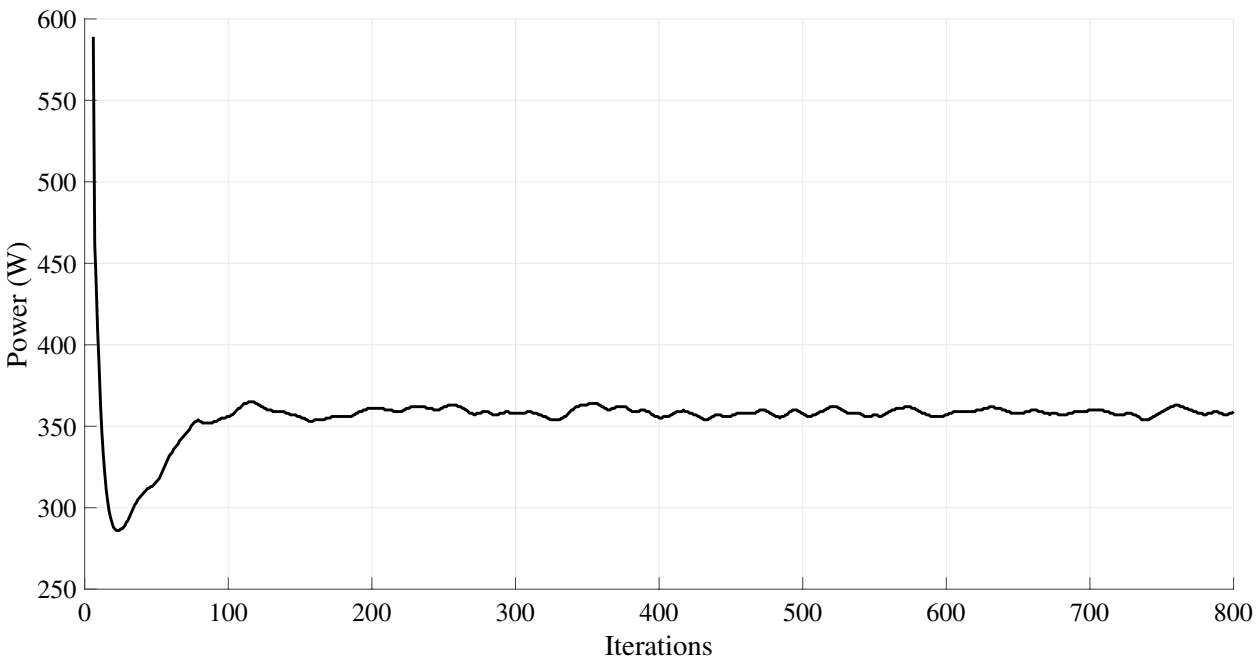



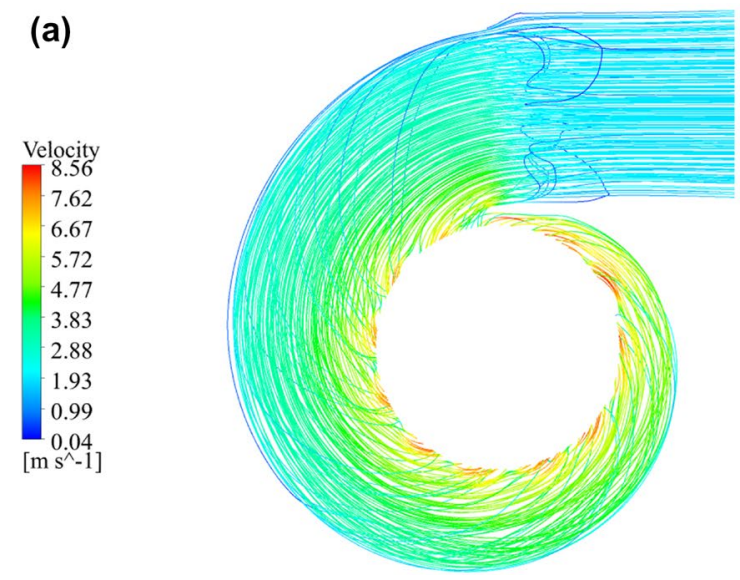

(b)

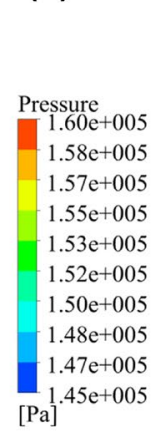

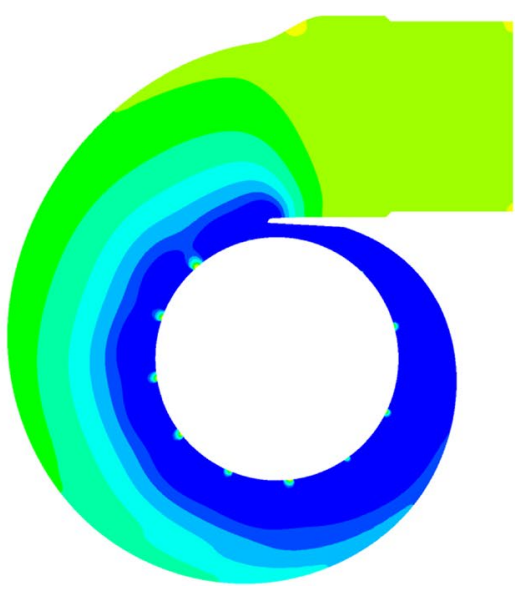

Fig. 7 a Streamlines in the volute. b Pressure field in a plane in the center of the volute
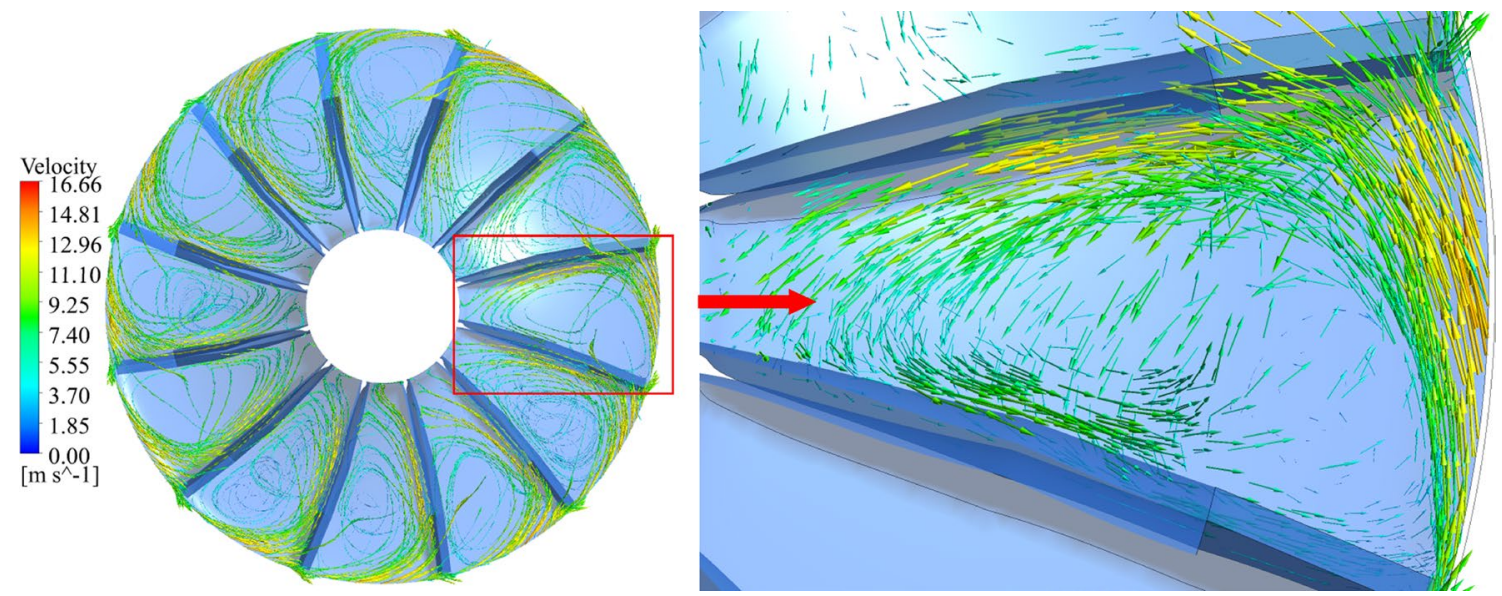

Fig. 8 Velocity vector field in the rotor

high values (higher than $12 \mathrm{~m} / \mathrm{s}$ ), being about 1.5-2.0 times the velocity at the entrance of the rotor. This high speed combined with the presence of sediments that flows together with water (such a phenomenon is common in Amazon rivers, as described by [28]), can damage the surfaces of the turbine components. This can cause a change in the flow pattern, leading to loss of efficiency, in addition to the increase in vibration.

It was observed that in the region of the blade suction, there is the presence of a high velocity gradient and these outcomes are also described in a similar case by [29], in his study on small Francis turbines with low flow rates. The visualization of this region is important due to the fact that these vortices creates low pressure regions, and the phenomenon of cavitation may occur. It is also highlighted in this figure that the behavior is not uniform among all the blades; thus, there is a loss of efficiency due to the imbalance in the distribution of fluid at the entrance to the rotor.
Figure $9 a$ and $b$ shows the tangential velocity contours in a plane through the center of the volute, parallel to the axis of rotation. A reduction in tangential velocity at the tip of the blade is observed. This occurs due to the steep flow curve, as shown in Fig. 9a.

Through Fig. 9b, a high reduction in the fluid pressure at the leading edge of the rotor blade is verified. This result comes from the stagnation pressure on the blades, which leads to a rapid reduction in the magnitude of the tangential velocity. The pressure at the leading edge of the blade is higher than at the end, i.e., the reduction in pressure at the suction blade side is due to the presence of a high flow velocity at the trailing edge. The contours of the pressure and velocity fields demonstrate that this turbine behaves similarly to high efficiency turbines such as Francis $[24,27]$ and Kaplan [30], even operating at very low head and flow rates. As shown in Fig. 10, the flow exits from the volute inlet to the rotating domain, where recirculations occur due to the sudden changing of the flow in the suction 
(a)

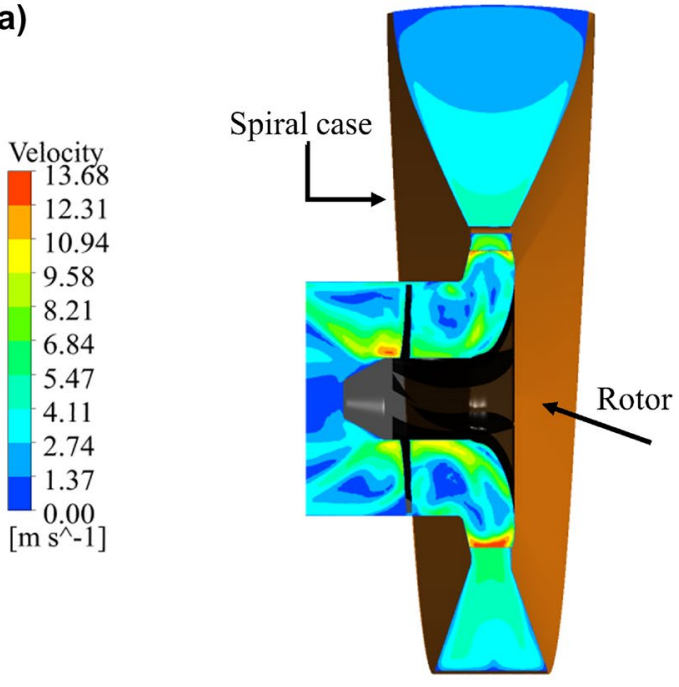

(b)

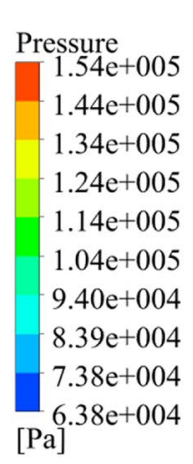

Fig. 9 a Tangential velocity variation. b Pressure distribution in the volute

tube. The maximum flow velocity was of $16.66 \mathrm{~m} / \mathrm{s}$ near the leading edge of the blades.

To show a comparison between the Indalma turbine and others available in the literature, Fig. 11 presents hydraulic efficiency at different volume flow rates and rotational speeds, showing that the performance trend is similar among conventional turbines. The results are compared to the data obtained by [5]. The highest turbine efficiency point of $80.8 \%$ is found at a flow rate of $0.012 \mathrm{~m}^{3} / \mathrm{s}$ and a rotational speed of $1460 \mathrm{rpm}$ which is considered the ideal (nominal) operating point for this Indalma turbine.

The efficiency of the turbine is calculated using the ratio $\eta_{h}=(M \cdot \omega) / \rho g Q H$, where $M$ is the torque produced

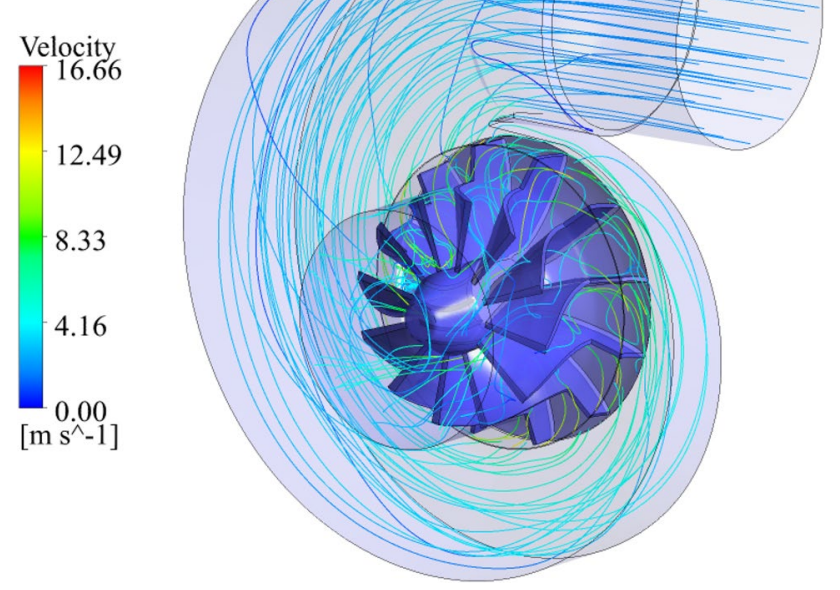

Fig. 10 Tangential velocity along the computational domain by the runner, $\omega$ is the rotating speed of the runner, $\rho$ is the water density, $g$ is the magnitude if gravitational acceleration, $H$ is the working water head and $Q$ is the discharge flow rate.

The efficiency curve of the Indalma turbine (black solid line in Fig. 11) was obtained from a curve fitting of the experimental results, using a second degree polynomial function only for the purpose of illustrating the tendency of its behavior to other flow rates, being necessary further evaluations. Note that the best operating point is almost the same in both cases, CFD and experiments for the Indalma turbine. Comparing with Francis and propeller turbines, Indalma turbine efficiency decreases markedly if it is operating out of the design condition, unlike turbines such as Crossflow and Pelton [31]. In addition, conventional turbines have higher efficiency than Indalma turbine, but for higher net head. Also, conventional turbines have high construction complexity, needing a stagger angle of guide vanes. For example, Pelton turbine needs a valve and deflector plate, while the Kaplan turbine needs a stagger angle of rotor blades to regulate flow, increasing production costs [32]. Therefore, Indalma turbine is an interesting alternative for small energy demand and low net head.

In Fig. 12, the behavior of the overall efficiency of the Indalma turbine is depicted, for the operation points described in Table 2. It is noteworthy that the values of the mechanical efficiency used in this work were taken from the research developed by [5] and applied to the total efficiency equation used here. The total efficiency is defined by the product of hydraulic and mechanical efficiencies, $\eta=\eta_{m} \cdot \eta_{t}$. From this equation, the investigation was made considering the total efficiency of the pico-turbine 

typical hydro-turbines
Fig. 11 Efficiency curves of

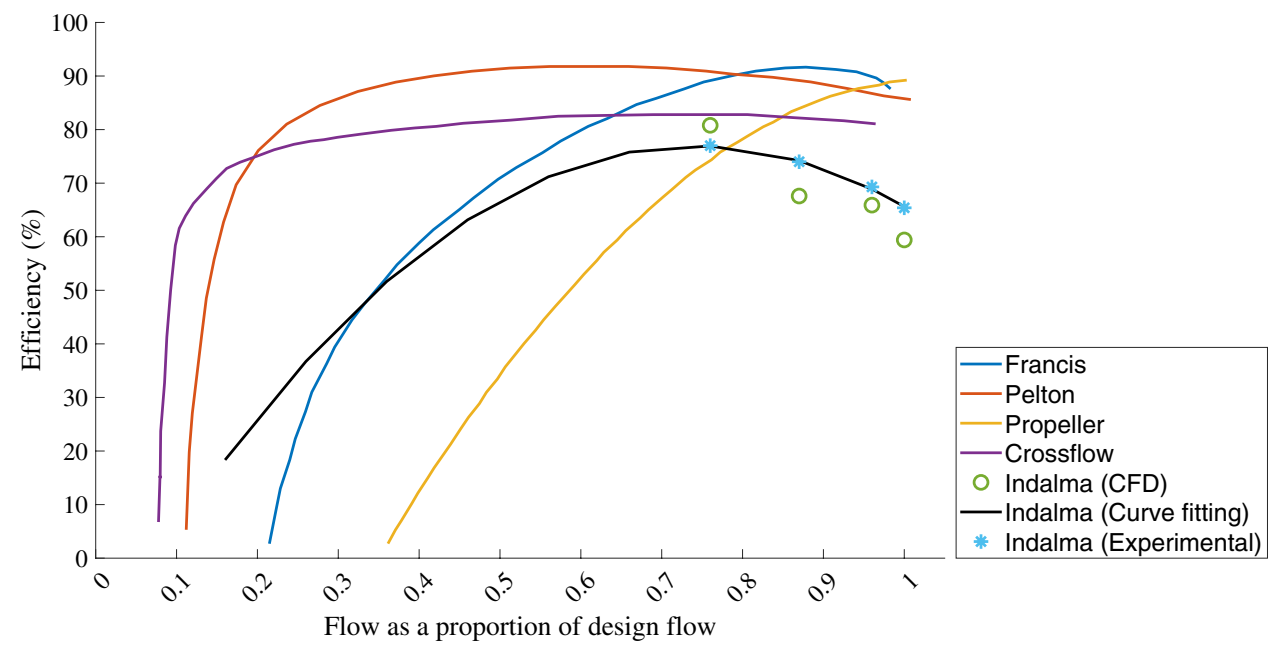

Fig. 12 Efficiency curves at 4, 5.5 and $7 \mathrm{~m}$ head

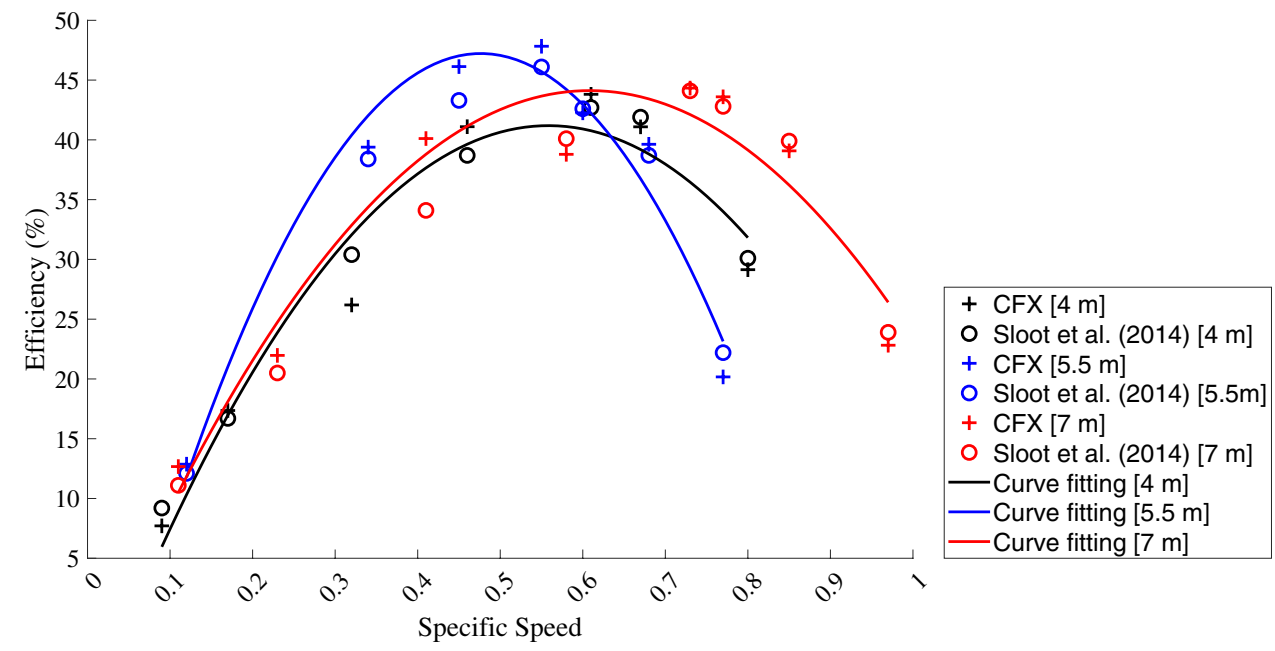

at different heads, in order to verify its operation when this parameter is changed.

Through Fig. 12, it was found that the numerical results agree well with the experimental data from [5]. The maximum efficiencies found were $47.83 \%$ for a $5.5 \mathrm{~m}, 44.33 \%$ for $7 \mathrm{~m}$ and $43.81 \%$ for $4 \mathrm{~m}$ of head. The overall efficiency of the turbine remains almost the same when the head is changed, even with the significant increase in flow, resulting in a substantial increase in the potential energy. This behavior is similar to those found by [33], which illustrates that the efficiency in low head of pico-turbines tends to be maintained without great variations when changing the head into this proportion.

The power generated by a turbine is proportional to the flow rate and the net head. It is common to represent the hydrodynamic behavior of a hydraulic turbine through the dimensionless specific speed, according to the equation $N_{s}=\omega Q^{1 / 2} / h^{3 / 4}$, where $\omega(\mathrm{rad} / \mathrm{s})$ represents angular velocity, $Q$ the flow rate $\left(\mathrm{m}^{3} / \mathrm{s}\right)$ and $h=g \cdot H$, where $g\left(\mathrm{~m} / \mathrm{s}^{2}\right)$ is the acceleration due to gravity and $H$ is the head $(\mathrm{m})$. When the turbine operates at zero flow, the total hydrostatic load of the project is determined, but the power generated by the turbine is zero [32].

In Fig. 13, as the flow decreases and the rotation increases (in terms of specific speed), the power generated increases until reaching the maximum generation for a specific dimensionless speed of 0.60. The maximum generated power found was $364.76 \mathrm{~W}$ for the rotation of $930 \mathrm{rpm}, 219.16 \mathrm{~W}$ for the rotation of $790 \mathrm{rpm}$ and of $524.20 \mathrm{~W}$ for the rotation of $1050 \mathrm{rpm}$ for the head of 5.5, 4 and $7 \mathrm{~m}$, respectively. Also, the results obtained have higher differences at low efficiency operation points. As described by [34] and [35], this problem is common in computational fluid dynamics, because, despite the notorious evolution of CFD, some phenomena that occur outside of the design point are not so well described in computational models. Thus, the results obtained were 
Fig. 13 Power curve at 4, 5.5 and $7 \mathrm{~m}$ head

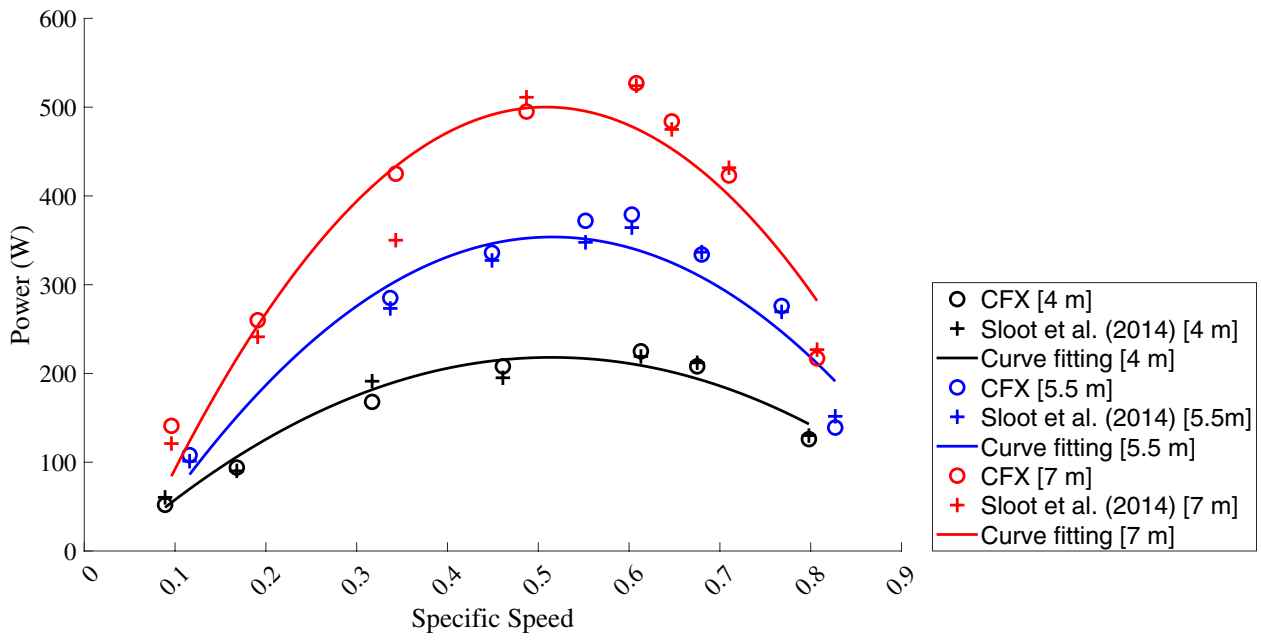

considered satisfactory, suggesting that the computational modeling implemented in this work approaches the real behavior of the turbomachinery under the conditions studied here.

The importance of these last two figures is that hydraulic turbines have a quick response in changing the operating configuration. The Indalma turbine does not have a sophisticated flow controller, and improper use of this equipment can cause the turbine rotor to shift from low to high speed rapidly, even leading to damage the mechanical and electrical systems. Therefore, the choice of operating point must meet the electrical output requirements without endangering the turbine from operating in configurations that may lead to cavitation arising or reduced efficiency due to operation outside proper range.

\section{Conclusions}

This work presents a hydrodynamic study of an Indalma pico-turbine, employing CFD. Using the RANS technique to turbulence modeling, it was possible to analyze the flow behavior through streamlines, pressure and velocity fields in the center planes. The results demonstrate that the hydraulic efficiency of the pico-turbine is similar to that of conventional ones, even operating under conditions of low head and flows, reaching $80.8 \%$ efficiency. However, its behavior decreases sharply when operating at very low flow rates in relation to the design point, similarly to that of turbines such as Francis and propeller. It was possible to identify that the results obtained have good agreement with the experimental data of [5]. For a head of $4 \mathrm{~m}$, a maximum power of approximately $219.16 \mathrm{~W}$ was found, at $5.5 \mathrm{~m}$ it was $364.76 \mathrm{~W}$, and at $7 \mathrm{~m}$ it was 524.20 W. These results are similar to those ones experimentally determined. In addition, the velocity vector field near the blade tip was shown and the formation of vortices between the blades was observed, which can generate low pressure regions, possibly causing cavitation effect. This effect can directly impact the efficiency of the turbine and its service life. The results obtained in this work could provide information about the flow along the components of this kind of turbomachinery, as well as predicting the generated power, resulting in a further improvements in design. Overall, the Indalma turbine is an interesting alternative for small energy demand and low net head, as it has good efficiency when compared to conventional turbines.

Acknowledgements The authors would like to thank the Brazilian National Council for Scientific and Technological Development (CNPq), the Coordination for the Improvement of Higher Education Personnel of the Brazilian government (CAPES), as well as PROCAD project (Agreement: 88881.200549/2018-01), and PROPESP/UFPA for financial support.

\section{Compliance with ethical standards}

Conflict of interest The authors declare that there is no conflict of interests regarding the publication of this article.

\section{References}

1. ANEEL (2020) SIGA-Sistema de Informações de Geração da ANEEL. https://bityli.com/4hc0E. Accessed 25 Aug 2020

2. Zhou D, Deng ZD (2017) Ultra-low-head hydroelectric technology: a review. Renew Sustain Energy Rev 78:23-30

3. Janjua AB, Khalil MS, Saeed M, Butt FS, Badar AW (2020) Static and dynamic computational analysis of Kaplan turbine runner by varying blade profile. Energy Sustain Dev 58:90-99

4. Santander OLS (2015) Montagem e instrumentação de uma bancada para turbina hidráulica. University of Brasília, Brazil

5. Donald RM, Sloot N (2014) Experimental and numerical study of the performance characteristics of a Pico Hydro turbine manufactured by Indalma Industries Inc. Anton de Kom Universiteit van Suriname, Suriname 
6. Els RV (2010) Eletrificação Rural em Santarém: Contribuição das Microcentrais. Revista Brasileira de Energia 1(16):35-46

7. Sepúlveda S, Wilkinson J, Tiburcio B, Herrera S (2008) Agroenergia e desenvolvimento de comunidades rurais isoladas, Série Desenvolvimento Rural Sustentável v.7, Instituto Interamericano de Cooperação para a Agricultura (IICA), Brasília, DF, Brazil

8. Oliveira DS, Rosa SSF, Noleto LG (2015) Modeling and experimental evaluation in the new hydraulic turbine used in the Amazon region. Glob J Eng Sci Res Manag 2(8):57-66

9. Adhikari RC, Vaz J, Wood D (2016) Cavitation inception in crossflow hydro turbines. Energies 9(4):237

10. Filho TGL, Lemos H, Nogueira FJH (2006) Estudo para energização de comunidade isolada na Amazônia: projeto microcentral Canaã. In: Proceedings of the $6^{\circ}$ Encontro de Energia no Meio Rural

11. BF EJF (2008) Tecnologias de energias renováveis: sistemas híbridos, pequenos aproveitamentos hidroelétricos, combustão e gasificação de biomassa sólida, biodiesel e óleo vegetal in natura. Ministério de Minas e Energia (MME)

12. Tavares ITB (2014) A influência de difusor na eficiência de uma turbina hidréulica. Undergraduate thesis, University of Brasélia, Brasélia, Brazil

13. Sloot NMD, Donald RM, Nannan NR, Els RV (2015) Experimental and numerical study of the performance characteristics of a Pico hydro turbine manufactured by Indalma industries INC. In: Conference proceedings ISSN: 2176-5480

14. Goyal R, Gandhi BK (2018) Review of hydrodynamics instabilities in Francis turbine during off-design and transient operations. Renew Energy 116:697-709

15. Heinz S (2020) A review of hybrid RANS-LES methods for turbulent flows: concepts and applications. Prog Aerosp Sci 114:100597

16. Badshah M, Badshah S, Jan S (2020) Comparison of computational fluid dynamics and fluid structure interaction models for the performance prediction of tidal current turbines. J Ocean Eng Sci 5(2):164-172

17. Davidson PA (2004) Turbulence: an introduction for scientists and engineers. Oxford University Press, Oxford

18. Silva PASF, Shinomiya LD, Oliveira TF, Vaz JRP, Mesquita ALA, Junior ACPB (2017) Analysis of cavitation for the optimized design of hydrokinetic turbines using BEM. Appl Energy 185:1281-1291

19. Qian ZD, Li W, Huai WX, Wu YL (2012) The effect of runner cone design on pressure oscillation characteristics in a Francis hydraulic turbine. Proc Inst Mech Eng Part A J Power Energy 226(1):137-150

20. Prasad V (2012) Numerical simulation for flow characteristics of axial flow hydraulic turbine runner. Energy Procedia 14:2060-2065

21. Antunes Junior GJ, Lima AK, Vaz JRP, Lins EF (2020) Computational analysis of vortex rope in a hydroturbine of Tucuruí dam. J Braz Soc Mech Sci Eng 42:313. https://doi.org/10.1007/s4043 0-020-02401-7

22. Sagol E, Reggio M, llinca A (2012) Assessment of two-equation turbulence models and validation of the performance characteristics of an experimental wind turbine by CFD. ISRN Mech Eng. https://doi.org/10.5402/2012/428671
23. Ansys (2016) "ANSYS CFX-solver theory guide", version 16.0

24. Saeed RA, Popov V, Galybin AN (2012) Complete Francis turbine flow simulation at Derbendikan power station. In: Proceedings of the advances in fluid mechanics IX. WIT Press, Split, Croatia, pp 49-57

25. Unterluggauer J, Sulzgruber V, Doujak E, Bauer C (2020) Experimental and numerical study of a prototype Francis turbine startup. Renew Energy 157:1212-1221

26. Zhang M, Huang B, Wu Q, Zhang M, Wang G (2020) The interaction between the transient cavitating flow and hydrodynamic performance around a pitching hydrofoil. Renew Energy 161:1276-1291

27. Mauro S, Lanzafame R, Brusca S, Messina M (2019) Unsteady computational fluid dynamics analysis of the hydrodynamic instabilities in a reversible Francis turbine used in a storage plant. Heliyon 5(9):e02441

28. Coelho JG, Cunha AC, Blanco CJC, Oliveira G, Pinho FAA, Oliveira TF, Brasil ACP (2013) Experimental measurements and numerical simulation for use of residual flow of the hydroelectric power. In: Proceedings of the XXXIV Iberian Latin-American Congress on Computational Methods in Engineering

29. Laouari A, Ghenaiet A (2016) Simulations of steady cavitating flow in a small Francis turbine. Int J Rotating Mach 2016:1-15. https://doi.org/10.1155/2016/4851454

30. Kaniecki M, Krzemianowski Z, Banaszek M (2011) Computational fluid dynamics simulations of small capacity Kaplan turbines. Trans Inst Fluid-Flow Mach 123:71-84

31. Okedu K, Uhunmwangho R, Odje M (2020) Harnessing the potential of small hydro power in Cross River state of Southern Nigeria. Sustain Energy Technol Assess 37:100617

32. Dixon SL, Hall C (2013) Fluid mechanics and thermodynamics of turbomachinery. Butterworth-Heinemann, Oxford

33. Williamson S, Stark B, Booker J (2014) Low head pic hydro turbine selection using a multi-criteria analysis. Renew Energy 61:43-50

34. Dorfler P, Sick M, Coutu A (2012) Flow-induced pulsation and vibration in hydroelectric machinery: engineer's guidebook for planning, design and troubleshooting. Springer, Berlin

35. Braga D, Coelho D, Soeiro NS, Melo GSV, Sanz JPM (2015) Construção de modelo numérico de uma turbina francis utilizando mvf em regime permanente com validação. In: Proceedings of the XXXIV Iberian Latin-American Congress on Computational Methods in Engineering. Congresso de Inovação Tecnológica em Energia Elétrica - CITENEL e o Seminário de Eficiência Energética no Setor Elétrico - SEENEL

36. Wilcox DC (1998) Turbulence modeling for CFD, 2nd edn. DCW Industries, La Canada Flintridge

Publisher's Note Springer Nature remains neutral with regard to jurisdictional claims in published maps and institutional affiliations. 